\title{
La construcción mediática de perdedores $y$ vencedores en el campo político: Análisis de las metáforas, tópicos y lexicalización ${ }^{*}$
}

\author{
NATALÍ HERNÁNDEZ MIRANDA** \\ pindaro0710@gmail.com
}

Forma de citar este artículo: Hernández Miranda, N. (2014). La construcción mediática de perdedores y vencedores en el campo político: Análisis de las metáforas, tópicos y lexicalización. Cuadernos de Lingüística Hispánica, 25, 81-98. Tunja: Uptc.

* Artículo de investigación. Muestra parte del resultado de un proyecto investigativo, que se enmarca en la línea de investigación Análisis del Discurso Mediático, presentado para obtener el título de profesional en Linguística y Literatura de la Universidad de Cartagena.

** Profesional en Linguística y Literatura. Universidad de Cartagena, Colombia. 


\title{
Resumen
}

Este artículo es una muestra de los aspectos teóricos, metodológicos y los resultados de un proyecto de investigación terminada, titulada: Análisis del discurso periodístico sobre la reelección del expresidente Álvaro Uribe Vélez: un caso de legitimación en la revista Semana (2005-2006). En esta investigación se da cuenta de cómo algunos recursos del discurso como la lexicalización, la metáfora y la topicalización se usan como estrategias de legitimación de algunos actores políticos y sus acciones descritas en la revista Semana; así, se contribuyó, en el 2006, a la reelección presidencial de Álvaro Uribe Vélez, una de las figuras políticas más controversiales de nuestro país actualmente.

Palabras clave: Análisis crítico del discurso, ideología, hegemonía, legitimación, metáfora, lexicalización, topicalización.

\section{Media construction of losers and winners in the political field: analysis of metaphors, topics and lexicalization}

\begin{abstract}
This article is a sample of the theoretical and methodological aspects, and the results of a finished research project entitled "Journalistic discourse analysis of the reelection of former president Álvaro Uribe Vélez: a case of legitimation in Semana magazine (2005-2006)". This research project accounts for the manner in which some discursive resources, such as lexicalization, metaphor, and topicalization are used as legitimation strategies of some political actors and their actions, as depicted in Semana magazine; contributing to the presidential reelection of Álvaro Uribe Vélez in 2006, currently one of the most controversial political figures in our country.
\end{abstract}

Keywords: critical discourse analysis, ideology, hegemony, legitimation, metaphor, lexicalization, topicalization 


\section{La construction de perdants et vainqueurs sur le champ politique: analyse des métaphores, topiques et lexicalisation}

\section{Résumé}

Cet article est un échantillon des aspects théoriques, méthodologiques et les résultats d'un projet de recherche terminée, ayant comme titre: Analyse du discours journalistique sur la réélection de l'ex-président Álvaro Uribe Vélez: un cas de légitimation dans la revue Semana (2005-2006). Dans cette recherche, il est rapporté comment quelques sources du discours tels que la lexicalisation, la métaphore et la topicalisation, sont utilisés actuellement, comme des stratégies de légitimation de quelques acteurs politiques et leurs actions décrites dans la revue Semana. Ainsi, on a contribué, en 2006, à la réélection présidentielle d'Álvaro Uribe Vélez, un des personnages politiques qui génère le plus de controverse dans notre pays actuellement.

Mots clés: Analyse critique du discours, idéologie, hégémonie, légitimation, métaphore, lexicalisation, topicalisation.

\section{A construção mediática de perdedores e vencedores no campo político: Análise das metáforas, tópicos e lexicalização}

\section{Resumo}

Este artigo é uma amostra dos aspectos teóricos, metodológicos e os resultados de um projeto de pesquisa terminada, titulada: Análisis del discurso periodístico sobre la reelección del ex presidente Álvaro Uribe Vélez: un caso de legitimación en la revista Semana (2005-2006). Nesta pesquisa pode ver-se como alguns recursos do discurso como a lexicalização, a metáfora e a topicalização são usados como estratégias de legitimação de alguns atores políticos e suas ações descritas na revista Semana; assim, contribuiu-se, em 2006, à reeleição presidencial de Álvaro Uribe Vélez, uma das figuras políticas de maior controvérsia de nosso país atualmente.

Palavras chave: Análise crítico do discurso, ideologia, hegemonia, legitimação, metáfora, lexicalização, topicalização. 


\section{Introducción}

Los medios de comunicación son una de las instituciones modernas con capacidad de difundir masivamente y controlar la opinión pública, las representaciones, y por tanto, las acciones de los sujetos. Contrario a la idea de transmitir un discurso transparente y neutro, cuyo único fin es informar a los receptores el "estado de las cosas", en los discursos masivos como el mediático, se construyen las valoraciones sociales, creencias y opiniones en torno a los acontecimientos. Así, en todo discurso es posible identificar posiciones frente a los eventos, frente a la organización social, a las instituciones y frente a los sujetos como miembros de grupos sociales.

Los medios de comunicación, como afirma Patrick Charaudeau (2005), seleccionan lo que muestran del estado de las cosas en el mundo. Así, en cierto momento noticioso acentuarán más la atención sobre las víctimas, el victimario, el perseguidor 0 sobre el salvador, en función de lo que desean comunicar. Cada enfoque de las noticias despertará en la mente de los receptores anhelos, miedos, imágenes diferentes, por lo que la responsabilidad de la "máquina", como denomina Charaudeau a los medios de comunicación, es muy compleja, dado todo el equipo involucrado. Lo cierto es que lo medios de comunicación se encargan de seleccionar, realizar y poner en escena los eventos con el fin de lograr un efecto emocional en los receptores; pero cuyo único fin democrático tendría que ser informar.

Esa manera de organizar la información tiene que ver con la posición de los medios de comunicación frente a los sujetos de las noticias y las situaciones; dicha organización, ejerce una influencia decisiva sobre la manera en que los receptores representan 0 definen un acontecimiento o una situación en sus modelos mentales. Tales hechos, hacen interesante analizar la manera en que la revista Semana se posiciona frente a la reelección presidencial de Álvaro Uribe Vélez en el período 2005- 2006.

La finalidad de este trabajo es dilucidar las estrategias de legitimación y recursos lingüísticos que representan a los sujetos sociales involucrados en la reelección presidencial, en el período previamente mencionado. Por lo cual se pregunta: ¿cuáles son las estrategias discursivas y los recursos lingüísticos utilizados por la revista Semana en la sección Nación para legitimar la reelección del expresidente Álvaro Uribe Vélez?

En concordancia con lo anterior, se plantean los siguientes objetivos; en primer lugar, describir la manera como se legitima la reelección presidencial de Álvaro Uribe Vélez en las noticias y artículos de la revista Semana en la sección Nación (2005- 2006), mediante un análisis crítico discursivo. En segundo lugar, determinar los tópicos del 
discurso más relevantes; identificar y seleccionar las estrategias de lexicalización y las metáforas utilizadas para la construcción social de los actores discursivos. En tercer lugar, analizar de qué manera incidió el discurso periodístico de la revista Semana sobre la reelección presidencial en el pensamiento colectivo y cotidiano de la ciudadanía. Todo con el fin de dar cuenta de la construcción de sujetos polarizados y la legitimación de representaciones sociales en el contexto de la reelección de álvaro Uribe Vélez por parte de la revista Semana.

\section{Marco teórico y metodológico}

La investigación se llevó a cabo desde la perspectiva interdisciplinaria de análisis crítico del discurso, particularmente desde el enfoque sociológico de Norman Fairclough (2001, 2003) y el enfoque sociocognitivo de Van Dijk (1990, 1995, 1997, 2003, 2004, 2006). De igual manera, el concepto de poder de Foucault $(1999,2000)$ y su vinculación con la ideología. Conceptos que se constituyen en nociones fundamentales para abordar las estrategias discursivas legitimadoras de la reelección presidencial que llevaron a que en mayo 28 del 2006 se reeligiera a Álvaro Uribe Vélez.

Este análisis se centró en la identificación de los recursos discursivos legitimadores como son: las metáforas, la lexicalización y la topicalización que, al pasar desapercibidas para los usuarios del lenguaje, no se le presta atención a su poder constructivo y reproductivo en el lenguaje.

En primer lugar, la metáfora la entendemos desde la perspectiva de Lakoff y Johnson (2004), como el recurso del lenguaje que impregna la vida cotidiana y va más allá de un adorno poético del lenguaje, pues contribuye a estructurar lo que se piensa y a determinar las acciones, orientando las creencias y conocimientos. Según los autores, las metáforas ayudan a conceptualizar las experiencias y a estructurar los conceptos que usamos cotidianamente, realidad que se revela en nuestro lenguaje en forma de expresiones metafóricas. En ese sentido, el discurso político y el discurso mediático, por pertenecer a los discursos de masas o propagandísticos, como los denomina Charaudeau (2005) están ligados a las formas de pensar y actuar en la sociedad, a partir de los valores y referentes compartidos.

Lo interesante y relevante de estudiar las metáforas se encuentra en la manera como pasa desapercibida en el uso, en su alto contenido persuasivo y en su vinculación con las ideologías, lo que las constituye en un importante recurso, como dicen Lakoff y Johnson (2004), "para la construcción de la realidad social y política" (p. 201) que permite "concebir una cosa en términos de otra" (2004: p. 74). Esto implica que la metáfora es un fenómeno del pensamiento, de acuerdo con la manera como estructuramos los conceptos 
en la mente. Por ejemplo, podemos concebir el amor como una guerra, la política como un juego o la política como un circo; el hecho de pensar situaciones, cosas y personas en términos de otras cosas nos revela el carácter ideológico de las metáforas e implica, además que ellas marcan la manera como nos relacionamos con las personas en cierta cultura, como las definimos o representamos.

Lakoffy Johnson (2004) presentan tres tipos de metáforas: estructurales, ontológicas y orientaciones.

Las metáforas estructurales, se encargan de estructurar un concepto en términos de otro mejor elaborado. La base experiencial en esas metáforas es lo que las distingue de las demás, ya que es el reflejo de aspectos de la cultura en que se usan; es decir, al compararlas con las de otra cultura, estas metáforas pueden variar. Por ejemplo, la consideración de que una discusión es una guerra en nuestra cultura; en otras culturas, una discusión puede ser un juego o un negocio.

Las metáforas ontológicas, ayudan a entender algunas experiencias en términos de entidades, sustancias, recipientes, características humanas o actividades humanas. El fin de este tipo de metáfora es que aprehendamos con más facilidad conceptos y fenómenos que no son tangibles. Por ejemplo, entendiendo la inflación económica en términos de persona: la inflación nos va a matar.

Las Metáforas orientaciones, nos ayudan a orientar y organizar conceptos en relación con otros "usando términos espaciales"; hacen uso de las experiencias más básicas en cuestiones orientacionales en el ser humano, como "arriba-abajo, dentrofuera, delante-atrás, profundo-superficial, central-periférico" (Lakoff y Johnson, 2004, p. 50), que desde nuestro cuerpo y, por ende desde nuestra experiencia, nos posibilitan comprender el mundo en términos espaciales, por ejemplo: mejor es arriba.

En segundo lugar, la lexicalización es otro recurso discursivo encontrado en el corpus que nos permitió entender y explicar la manera como se construyen representaciones de los sujetos políticos y sus acciones con fines definidamente políticos y estratégicos. La lexicalización es una de las formas más obvias de expresión ideológica en el discurso. Se trata de la selección léxica de una palabra en lugar de otras para expresar un concepto en un contexto determinado. Se escogen palabras que se refieran al otro grupo de tal forma que ofrezca una opinión sobre ellos. Es así como creamos una polarización entre "nosotros" y "ellos", tal como explica Van Dijk en su cuadrado ideológico; el grupo "nosotros" es caracterizado con palabras que denotan cualidades, virtudes, logros, futuro y "los otros" con denominaciones no positivas como estáticos, negativos, poco interesantes; todo en pro de crear una imagen diferenciada de "nosotros" y "ellos" ante los demás. 
En tercer lugar, encontramos la topicalización que es un importante recurso del lenguaje que permite resaltar los temas importantes del discurso. Es usado en gran medida por la prensa mediante la ubicación de los temas de las noticias en los titulares, resúmenes, encabezados, etc. Lo que sirve para marcar en la mente de los receptores los tópicos más importantes del discurso. Esos temas que los receptores rescatan en el discurso responden a la formación social, cultural e ideológica que este tenga. Los tópicos condicionan los discursos y las acciones del receptor porque se fijan en la mente, conformando ideologías. Influyendo, como señala Van Dijk (2006), en la formación de los modelos mentales del acontecimiento que trata el discurso, es decir, en la representación de las personas, situaciones, etc.

\section{Resultados}

Teniendo en cuenta las anteriores categorías, este análisis se dividió en tres partes: uno dedicado al análisis de la lexicalización, una segunda parte dedicada al análisis de la topicalización, y una tercera parte que expone el análisis de las metáforas más recurrentes y reveladoras, las estructurales y ontológicas.

\subsection{Lo que revelan las palabras: lexicalización}

Al revisar el corpus de la revista Semana notamos que al expresidente Uribe se le presentó alejado de conflictos, con una nominalización formal haciendo siempre referencia a su labor de presidente del país y con su respectivo nombre propio: Álvaro Uribe, Uribe; acompañados de algunos calificativos favorecedores "fenómeno sólido". A los Uribistas se les presentó como bravos, pertenecientes a un grupo sólido, "el uribismo", con calificativos que hacen alusión a la fuerza. Se le presenta mediante el discurso como líderes y administradores del país; con calificativos referentes a su carácter de ganadores, victoriosos y desbordantes aludiendo a su favorabilidad. Para ilustrar este fenómeno de polarización, observemos los siguientes ejemplos:

Álvaro Uribe Vélez: Uribe, candidato Uribe, Álvaro Uribe, presidente Uribe, el presidente, candidato, el presidente, el presidente Álvaro Uribe, gigante de las encuestas, el candidato Uribe, el fenómeno de Álvaro Uribe, un fenómeno tan sólido como Álvaro Uribe, el gobierno.

Frente a un gigante de las encuestas, como Álvaro Uribe, Pardo se ve como un Quijote. (Revista Semana, Domingo 3 julio 2005, «El Quijote»)

Uribistas o partidarios: el gobierno, alto gobierno, el victorioso tren gobiernista, el uribismo desbordante, el alto gobierno, gobierno Uribe, el gobierno, fuerzas: 
Los azules se montaron en el victorioso tren gobiernista, que los empuja en las encuestas, pero les eclipsa la identidad. (Revista Semana, Domingo 12 de febrero 2006, «Un año de transición»)

En oposición a lo anterior, a los actores políticos no Uribistas, se les presenta siempre en conflicto entre ellos mismos, en competencia, en lucha. Asumiendo también posiciones críticas frente al gobierno en posición de contradictores, enemigos, opositores, competidores, rivales. Con características ligadas a la debilidad y la pequeñez, a la reducción, debilidad, hostilidad, radicalidad, inflexibilidad, etc. En tal representación se usan palabras específicas como: antiuribistas, aspirantes, los candidatos, la oposición, los trapecistas, reducida pero ruidosa oposición, conspicuos contradictores, contradictores, competidores, candidatos presidenciales, los enemigos de la reelección, candidatos de la oposición, el enemigo, los competidores de Álvaro Uribe, candidatos de oposición, rivales, antiuribista, enanos:

Uribe llega a la campaña de 2006 en una posición más cómoda. Mantiene una alta popularidad, a pesar del leve desgaste de los últimos meses. Y les quitó a sus rivales, todos enanos a su lado en materia de intención de votos, la bandera de la crítica a la política de paz. (Revista Semana, Domingo 12 de febrero 2006, «Un año de transición»)

"Y, si no quedan por fuera por no alcanzar el umbral, las fuerzas pequeñas (Peñalosa, Mockus, Alas/Equipo Colombia, Convergencia Ciudadana, Moreno de Caro, C-4 y otros nueve inscritos) estarían en el rango de tres a cinco.”. (Revista Semana, Domingo 26 de febrero 2006, « Los dos uribes»)

Todas esas expresiones y los calificativos aquí presentados, caracterizan negativamente a los actores políticos de oposición como personas no aptas para dirigir un país por su poca capacidad de lucha y fortaleza, sobre todo en un contexto de confrontaciones armadas como fue el período anterior a la reelección presidencial en el 2006 en que imperó la política de seguridad democrática.

\subsection{Los tópicos en el discurso de la revista Semana: la primera reelección}

Los temas o tópicos más recurrentes en un discurso permiten reconocer el punto de vista del productor respecto a las situaciones o actores implicados. En el caso de la revista Semana, esos temas develan su visión respecto al proceso de reelección presidencial y sus actores. Estos tópicos fueron cinco: la debilidad, la desacreditación, la inconsistencia ideológica, la fragmentación política y el favoritismo de Uribe; teniendo siempre, como punto de comparación y contraste la aceptación hacia Álvaro Uribe Vélez: 


\subsubsection{La debilidad de la oposición política}

En este tópico la oposición se asocia con otros temas como la falta de consenso de estos para con sus propuestas políticas, lo poco atractivos que son para los actores políticos en el contexto nacional; temas que también ayudan a consolidar el tópico en cuestión:

Al final, sin embargo, Uribe mantuvo su alta aceptación y todos sus contradictores se desplomaron. (Revista Semana, Domingo 17 de julio 2005, « Oponerse Sale (aro»).

En Colombia la oposición aparenta no ser atractiva ni rentable. Menos aún, según las últimas encuestas, en una época de fuerte apego a quien ejerce el poder, como es el caso de Álvaro Uribe. (Revista Semana, Domingo 14 de agosto 2005, «Los trapecistas»)

Y Uribe, como una manera de neutralizar la reducida pero ruidosa oposición política, no ha tenido problema en vincular al gobierno -sobre todo al servicio exterior- a sus más conspicuos contradictores. (Revista Semana, Domingo 14 de agosto 2005, « Los trapecistas»)

En este tópico a la oposición se le caracteriza metafóricamente como estructuras débiles, desplomadas, poco atractivas, nada rentable, con poca aceptación por parte de los electores, con mala imagen ante los colombianos, reducida y ruidosa. Características que desfavorecen a los candidatos de la oposición.

\subsubsection{La desacreditación de las acciones de la oposición política}

Se resaltan las críticas de la oposición tildándolas de sistemáticas, radicales; nombradas en términos de ataques y daños al gobierno. No se exponen las razones por las que los opositores citan su voz de protesta para con el gobierno, se destacan en su lugar las molestias y los daños que causan estas críticas al mismo. Los opositores se presentan como obstructores; cuyas críticas, sin razón válida, se destacan el complot o capricho.

Para los uribistas, el origen liberal de Maya y de Hernández implica que forman parte de la oposición hace poco decretada por su partido, y se oponen al gobierno de manera sistemática. (Revista Semana, Domingo 14 de agosto 2005, «Los trapecistas»)

Andrés Pastrana es el líder del equipo, por su dimensión de ex presidente y porque en los últimos meses había asumido una de las líneas de oposición más vehementes. Se había opuesto a la reelección y criticaba duramente el proceso de paz con los paras. (Revista Semana, Domingo 14 de agosto 2005, «Los trapecistas»). 


\subsubsection{La inconsistencia ideológica y política de los opositores}

Se acentúan en las noticias las alianzas, volteretas, cambios de camisetas y cambios de banderas que caracterizan el panorama político colombiano del momento como desordenado:

La incoherencia es una característica muy arraigada de la política colombiana, que va de la mano con otra: el desgano hacia la oposición. (Revista Semana, Domingo 14 de agosto 2005, « Los trapecistas»)

A serpa, además, la opinión pública parece cobrarle las inconsistencias sobre propuestas contradictorias hechas antes del congreso liberal, y su falta de claridad sobre sus intenciones en la campaña. (Revista Semana, Domingo $17 \mathrm{de}$ julio 2005, « Oponerse Sale Caro»).

En síntesis, los políticos opositores son representados como sujetos incoherentes, poco serios y desordenados asumiendo papeles de payasos, trapecistas, etc. como veremos en el análisis de las metáforas estructurales.

\subsubsection{La fragmentación de los partidos políticos no uribistas}

Este tópico es el más frecuente dentro del corpus de noticias de la revista Semana; se trata de resaltar en las noticias los problemas internos que se dan en los partidos políticos como los desacuerdos, los escándalos del pasado y el cambio de partido de algunos de sus miembros. Este tópico se une con las metáforas ontológicas, los partidos políticos son objetos y las personas son objetos, aspecto que se desarrollará más adelante.

Los grupos políticos presentados reiteradas veces como divididos o fragmentados en las noticias del corpus son: el Polo Democrático y el Partido Liberal. Los temas que se reiteran en las noticias y que sustentan la idea de partidos en crisis o fragmentados son básicamente: las diferencias ideológicas, la mala imagen de los partidos, deserciones y competencias internas por el poder y la falta de liderazgo.

El del ex ministro Santos es, en fin, todo un salto con garrocha. Defensor decepcionado de la idea de fortalecer al liberalismo como tabla de salvación del sistema de partidos, (Revista Semana, Domingo 6 de marzo 2005, « Salto con Garrocha»)

Los rojos se fueron a la oposición, gracias a lo cual lograron el regreso del gavirismo, pero perdieron a casi toda su clase política, su gran fortaleza de los últimos años, hoy desplazada al uribismo. (Revista Semana, Domingo 12 de febrero 2006, «Un año de transición»). 


\subsubsection{Favoritismo de Álvaro Uribe}

Este tópico está presente a lo largo del corpus de noticias de la revista Semana, tiene que ver con la relevancia que se le brinda al tema de la popularidad y a la preferencia de los ciudadanos hacia la propuesta de seguridad democrática del expresidente Uribe Vélez. Este tema se muestra mediante el uso de cifras estadísticas que dan cuenta del favoritismo de Álvaro Uribe Vélez:

Es decir, contra un rival que ha tenido una popularidad de $\mathbf{7 0}$ por ciento durante tres años, una intención de voto cercana al 50 y una posición que, sumada a sus habilidades mediáticas, le permite copar el escenario político. (Revista Semana, Domingo 3 de abril 2005, «Al agua patos»).

Sus altos índices de aprobación -69 por ciento de opinión favorable en la última encuesta Invamer-Gallup- se deben fundamentalmente a que los colombianos consideran que la guerra contra las Farc ha sido exitosa. Un 73 por ciento considera que el país hoy es más seguro que hace un año. (Revista Semana, Domingo 12 febrero 2006, « El candidato Uribe»).

Este tema del favoritismo tiene una implicación muy importante y es que al afirmar que Uribe Vélez es el elegido de los colombianos aceptamos que el resto de candidatos no lo son. Quedan según el corpus, los actores políticos no uribistas disputándose unas cifras muy reducidas de intenciones de votos. Dado el carácter de objetividad y credibilidad que le imprimen los números o las cifras a los argumentos se puede concluir que la oposición política no tiene nada que hacer en una competencia en la que ya hay un ganador indiscutible.

Frente a un gigante de las encuestas, como Álvaro Uribe, Pardo se ve como un Quijote. (Revista Semana, Domingo 3 julio 2005, «El quijote»)

\subsection{Las metáforas como legitimadoras de la reelección de Álvaro Uribe Vélez}

En el corpus encontramos dos grandes grupos de metáforas como son las estructurales y ontológicas.

- Metáforas estructurales: La política es una guerra, La política es un viaje, La política es un terreno, El ejercicio de la política es un juego lúdicodeportivo, La política es un circo.

- Metáforas ontológicas: Las personas son animales, Los partidos políticos son objeto, Las personas son objetos, La fuerza es una persona. 
La metáfora la política es una guerra permite entender a los actores políticos como enemigos, rivales o contrincantes, aliados y víctimas. Los opositores al gobierno de Álvaro Uribe son presentados como enemigos y sus acciones son bélicas en contraposición a Álvaro Uribe Vélez que es presentado como una víctima cuyas acciones son de defensa lo que justifica y legitima sus acciones sobre los opositores:

Rodrigo Rivera, Antanas Mockus, Antonio Navarro, Horacio Serpa- cayeron en la tentación estratégica de levantar sus espadas contra el gobierno, convencidos de que se estaban subiendo a un tren imparable. (Revista Semana, Domingo 17 de julio 2005, « Oponerse Sale Caro»).

Se destacan en las noticias las características de los enemigos como débiles (necesitan el apoyo de los entes de control nacional), no tienen buenas tácticas de guerra, forman complot en contra del gobierno de Álvaro Uribe, no tienen capacidad de lucha o ataque, son pocos o reducidos:

Ni con los cálculos más alegres, la oposición alcanza mayoría. No obstante, la ventaja del Presidente-candidato en la puja por la Presidencia no se refleja en la competencia para el Congreso. (Revista Semana, Domingo 19 de febrero 2006, «El banderazo »)

La Corte Constitucional giró hacia el pragmatismo y la moderación en 2005. Sus enemigos de la derecha están apaciguados, pero los más progresistas están desencantados. (Revista Semana, Domingo 12 de febrero 2006, «Un año de transición»).

Al expresidente Álvaro Uribe se le presenta como un guerrero fortalecido, victorioso, con capacidad de convencimiento para establecer alianzas, y fuerte. Se muestra también al Uribismo como el único partido con la seguridad, preparado para cualquier misión, como es la presidencia de la república, por su coherencia, fortaleza, unión, capacidad de lucha, lo que los representa como un gran ejército:

El presidente Álvaro Uribe salió victorioso de las intensas batallas del último trimestre. Un período difícil, en el que enfrentó debates por la aprobación de la ley de Justicia y Paz, críticas por la entrega de 'Don Berna' y embates de varios competidores que se lanzaron al escenario con discursos antigobiernistas. (Revista Semana, Domingo 17 de julio 2005, «0ponerse Sale Caro»)

No pierde la oportunidad (Uribe) para neutralizar a sus enemigos políticos. (Revista Semana, Domingo 7 de agosto 2005, «Anatomía de un gobierno») 
En la metáfora la política es un juego los opositores son representados como personas que cambian de camiseta fácilmente, es decir, grupos políticos que son miedosos, no tienen estrategias de juego, son débiles. Álvaro Uribe es representado como un jugador hábil que siempre le lleva ventajas a sus contrincantes en todos los juegos: maratón (llega a la primera vuelta con ventaja), las apuestas (todos quieren apostar por él) y tiene cartas guardadas:

Tenía su carta guardada pero la sacó y ganó. Consiguió que el Congreso le aprobara la reelección y su popularidad salió ilesa a pesar de la lluvia de críticas por haberles entregado demasiadas concesiones a los congresistas para que la aprobaran. (Revista Semana, Domingo 7 de agosto 2005, «Anatomía de un gobierno»)

Por donde se le mire, el gobierno se anotó un gol. Dividió y puso a pelearse entre ellos, a sus enemigos del Polo. (Revista Semana, Domingo 29 de mayo 2005, « La hora del polo»)

Las metáforas la política es un terreno y la política es un viaje le permiten a la revista Semana resaltar la ventaja que, a su parecer, les lleva el presidente Álvaro Uribe Vélez a sus opositores, como ocurre en la política en términos de maratón; igualmente mostrar el buen camino que representa el partido de la $\mathrm{U}$ para los colombianos. Mediante estas dos metáforas, la política se concibe como un lugar y como en una serie de rutas por seguir:

Las encuestas indican que el electorado se apartará de la tradición y en 2006 no buscará cambio sino continuidad. (Revista Semana, Domingo 17 de julio 2005, «La fórmula de Navarro»)

En la metáfora la política es un viaje el partido de la $\mathrm{U}$, en cabeza del presidente Uribe, es representado como el mejor camino para seguir, el camino o ruta preferida por el pueblo colombiano, el camino a la paz; los partidos de oposición son caracterizados como: un retroceder en los avances del gobierno, ruta en la que pocos transitan, camino complicado problemático y lleno de obstáculos; camino deteriorado, oscuro, largo, difícil. Los opositores se representan como actores que no trabajan en equipo, es decir que cada uno va por su lado en busca de la presidencia o un puesto político:

El camino no es claro, en síntesis, para la misión que asumirá el Partido Liberal, bajo el liderazgo de César Gaviria, de asegurarse un futuro. Hay otros obstáculos, como las resistencias que genera en las bases la percepción de que el neoliberalismo se está tomando el partido. (Revista Semana, Domingo 5 junio 2005, «¿Habrá futuro?») 
El camino hacia la Presidencia, para Rafael Pardo, tiene muchas etapas: ganarle a Peñalosa la investidura de retador de Serpa; disputarle a este último la base liberal, y derrotar a un Uribe que no se va a dejar destronar fácilmente. (Revista Semana, Domingo 3 julio 2005, «El quijote»)

La metáfora la política es un circo presenta de manera sutil a los partidos políticos opositores como un lugar no seguro para que los trapecistas salten, porque se pone en riesgo su vida, es decir su ejercicio político. En contraste con la manera como se presenta el partido de la U, como el mejor y más seguro trapecio, en la que los trapecistas opositores pueden saltar. Esta metáfora contribuye a fijar en la mente el carácter inconsistente de los políticos opositores, la debilidad de la oposición, la corrupción que existe en la oposición y la fortaleza del partido de la U por tener a Álvaro Uribe Vélez, es decir su legitimación, porque despierta miedos hacia la oposición como la sensación de desprotección al elegirlos, la corrupción que hay en ellos y que colocaría en peligro la seguridad de Colombia:

Cuando la reforma política pretendía organizar partidos serios y con una línea ideológica, la política se parece cada vez más a un circo. (Revista Semana, Domingo 12 febrero 2006, «Un paso al centro»)

Saltos mortales que parecen ir en busca del gran columpio uribista que, según todas las encuestas más recientes, es el que vuela más alto y es más seguro. (Revista Semana, Domingo 14 de agosto 2005, «Los trapecistas»)

Hubo una larga serie de volteretas de última hora. Telésforo Pedraza, un conservador pastranista que mantuvo hasta hace muy poco una dura crítica a la reelección y al gobierno, saltó al trapecio del partido de 'La U'. (Revista Semana, Domingo 12 febrero 2006, «Un paso al centro»)

En cuanto a la metáfora ontológica las personas son animales, se hace mayor énfasis en la presentación de Álvaro Uribe como víctima de su enemigo las FARC, quien se le presenta como feroz y venenoso, cuyo único fin es desprestigiar, criticar, hacerle daño al gobierno. Las FARC se presentan como un enemigo nacional al que el gobierno estuvo a punto de destruir y para lo cual necesita más tiempo para consolidar su propósito, lo que funciona como la justificación de la necesidad de la reelección presidencial y la legitimación de la misma. En esta representación se muestra como el único mal de Colombia las FARC, un mal que sólo lo acabará él en su gobierno por lo que necesita ser reelegido:

Las Farc necesitan mostrar los dientes para desprestigiar la política de seguridad democrática. (Revista Semana, Sábado 30 de julio 2005, «El plan antipatriota »).

En palabras del propio Uribe, en que "la serpiente (la guerrilla) todavía está viva" y se necesita más tiempo para acabarla. (Revista Semana, Domingo 12 febrero 2006, « La otra batalla») 
Las metáforas ontológicas los partidos politicos son objetos, las personas son objetos y la fuerza es una persona, cumplen la función de representar unos actores políticos diferenciados: el partido de la U como fuerte, sólido, coherente, con capacidad para movilizar las fuerzas a su favor, con muy buenas bases; los partidos políticos opositores son representados como débiles, minoritarios, reducidos, fragmentados; representación que desde la metáfora contribuye a fijar los temas del discurso de una manera sutil:

Los partidos tradicionales se encuentran divididos por la reelección. (Revista Semana, Domingo 29 de mayo 2005, « La hora del polo»)

El episodio de la Ley de Garantías despertó los viejos fantasmas de divisiones y rencillas de la izquierda. (Revista Semana, Domingo 29 de mayo 2005, « La hora del polo»)

En términos de objetos, a Álvaro Uribe Vélez se le muestra poseedor de características de los objetos con los que se le representa. Por ejemplo, "el Teflón”, es decir como un objeto fuerte, que no hay forma de tocarlo, que nada le daña su imagen, que no se desgasta:

Después de estas movidas de fin de año, Uribe llega a la campaña de 2006 en una posición más cómoda. Mantiene una alta popularidad, a pesar del leve desgaste de los últimos meses. (Revista Semana, Domingo 12 de febrero 2006, «Un año de transición»).

No lo ha afectado un desgaste como los que sufrieron sus antecesores durante el final del cuatrienio. Al presidente Uribe no lo afectan el ejercicio del poder ni las dificultades. Es el consabido mandatario de teflón, a quien no se le pega nada malo. (Revista Semana, Domingo 17 de julio 2005, « Oponerse Sale Caro»).

Estas representaciones contribuyen a borrar la complejidad de la realidad política del momento y omitir las responsabilidades de Uribe en los diferentes escándalos de los que hablan las noticias en cuestión, y centrar en su lugar el foco solamente en la capacidad que tiene Álvaro Uribe en mantener su buena imagen. Estas metáforas previamente descritas le permiten a la revista Semana no efectuar mayores críticas, análisis y cuestionamiento a las acciones corruptas del gobierno del expresidente Álvaro Uribe Vélez.

\section{Discusión de los resultados: Análisis de las estrategias}

Mediante cada uno de los recursos discursivos legitimadores: lexicalización, tópicos y metáforas se omiten matices importantes de los acontecimientos políticos y sociales del momento, resaltando solamente partes de la complejidad de los eventos. Un ejemplo claro es lo que ocurre con las metáforas. 
Mediante la metáfora la política es una guerra, se ocultan temas controversiales como la ley de justicia y paz; los escándalos sobre corrupción; el fomento del clientelismo mediante los ofrecimientos de puestos en embajadas y ministerios a sus opositores políticos; las amenazas a los organismos de control; los escándalos por el paramilitarismo; la desigualdad en la financiación de las campañas y las fallas de la política de seguridad. Se resaltan los enfrentamientos y los combates, que parecen ubicar a los actores involucrados en una guerra realmente y a los receptores de las noticias, en una realidad diferente a la elección del mejor mandatario para la nación, parecen estar asistiendo a una guerra en la que se resalta, tanto la debilidad de los opositores, como la valentía, las estrategias y la fortaleza del gobierno de turno; con el fin de legitimarlo como el gobierno que Colombia necesita en la lucha contra los grupos armados.

La legitimación del entonces mandatario, se lleva a cabo de manera parecida con la metáfora: la política es un juego. Mediante ella se justifican las trampas, las malas acciones de los contrincantes y se dejan sin mayores críticas por parte de la revista Semana. Mediante esta metáfora se reduce la complejidad de la campaña presidencial a un simple juego, seleccionando, ordenando las acciones de los implicados y presentando como realidad los hechos relacionados con el juego en el cual Álvaro Uribe es un buen jugador y los opositores unos perdedores.

Con el uso de la metáfora la política es un viaje y la política es un terreno, se logra eliminar lo complejo de la situación política del momento como son los casos de corrupción, presentados mediante la metáfora como cambios de posición en los terrenos, la reglamentación de las campañas, como obstáculos, etc. En otras palabras, no se cuestionan esos cambios de partidos desde un punto de vista crítico.

La metáfora la política es un circo se usa para borrar los matices relacionados con la corrupción y el clientelismo presentándolos como ejercicios graciosos de actores de circo, lo que le quita seriedad al ejercicio de la política a la vez que se le borran las responsabilidades de los actores políticos. Se presenta el cambio de partido como algo divertido, en el cual los actores políticos saltan de un lugar a otro para divertir a un público. No se menciona a Álvaro Uribe Vélez como promotor del clientelismo con sus ofrecimientos políticos, ni al partido de la U como albergador de los políticos desertores e inconsistentes como los llaman en la revista. Se celebra solamente el poder de convocatoria que tiene el partido de la $\mathrm{U}$. 


\section{Conclusiones}

Como podemos ver, todos los anteriores recursos (la lexicalización, la topicalización y las metáforas) refuerzan las estrategias de representación social que funcionan como legitimadoras del poder de una manera sutil debido a la poca atención que se les presta. Todos estos recursos discursivos vehiculan las ideologías que controlan nuestras acciones y nos llevan a suponer que estamos actuando libremente siguiendo nuestra voluntad. En este estudio se revela, por ejemplo, la manera como estas estrategias legitimadoras (léxicas, semánticas) contribuyen a la representación de unos sujetos aptos, fuertes, coherentes y a otros como no preparados, corruptos, inconsistentes para llevar el mando de Colombia en el período 2006-2010, legitimando la reelección de Álvaro Uribe Vélez.

\section{Referencias bibliográficas}

Charaudeau, P. (2003). El discurso de la información: la construcción del espejo social. Barcelona: Gedisa.

Charaudeau, P. (2006). Lenguaje, acción, poder. De la identidad social a la identidad discursiva del sujeto. Estudios del discurso en Venezuela. pp. 51-69.Venezuela: FUNDACITE.

Charaudeau, P. (2005). ¿Nos manipulan los medios? Cuadernos de información y comunicación. Recuperado de http://www.ucm.es/BUCM/revistas/inf/11357991/articulos/ CIYC0505110319A.PDF

Fairclough, N. (1995). Introducción. En Critical discourse analysis. The critical study of language. pp. 1-20 London and New York: Longman. Traducción y adaptación de Federico Navarro para la cátedra de Lingüística General (Dr. Martín Menéndez).

Fairclough, N., \& Wodak, R. (2000). Análisis crítico del Discurso. El discurso como interacción social. pp. 367-404. Barcelona: Gedisa.

Foucault, M. (1999). El orden del discurso. Barcelona: Fábula Tusquets Editores.

Lakoff, G., \& Jhonson, M. (2004). Metáforas de la vida cotidiana. Barcelona: Cátedra. Traducción de Carmen González Marín.

Van Dijk, T. (1990). La noticia como discurso: comprensión, estructura y producción de la información. Barcelona: Paidós Comunicación.

Van Dijk, T. (Comp.) (2000a). El discurso como interacción social. Barcelona: Gedisa. 
Van Dijk, T. (2000b). El discurso como interacción en la sociedad. El discurso como interacción social. pp. 19-66. Barcelona: Gedisa.

Van Dijk, T. (2003). Ideología y discurso: una introducción multidisciplinaria. Barcelona: Ariel Lingüística.

Van Dijk, T. (2006). Ideología: un enfoque multidisciplinario. Barcelona: Editorial Gedisa.

Wodak, R. y Meyer, M. (2003). (Comp.). Métodos de análisis crítico del discurso. Barcelona: Gedisa Editorial. 